\title{
Grammatical Errors Produced by UGM English Department Students
}

\author{
Ikhwanuddin Hasan*, Aris Munandar \\ Universitas Gadjah Mada, Indonesia \\ *Email: ikhwanuddinhasan@gmail.com
}

\begin{abstract}
A B S T R A C T
This research attempts to identify the grammatical errors produced by students of the English Department of UGM year 2012 in their final paper of the writing class. In particular, it attempts to classify the errors based on Surface Strategy Taxonomy proposed by Dulay, Burt, and Krashen (1982). The data used in this research were taken from the submitted assignments of the English Department students of Universitas Gadjah Mada year 2012 in General English, particularly nine students in writing class. We found 178 errors in fourteen linguistic categories which are divided into four parts: omission, addition, misformation, and misordering. From all the four parts, we discovered that the most frequent errors found are in the part of misformation (97 errors; $54.49 \%$ ), followed by omission (38 errors; $31.11 \%$ ), misordering (22 errors; $12.78 \%$ ), and addition (20 errors; 11.11\%). However, in the linguistic categories, the three most frequent errors found are misformation of verbal (30 errors), misordering of complex sentence (20 errors), and omission of determiner (19 errors).
\end{abstract}

Keywords: errors, error analysis, grammatical errors, surface strategy taxonomy.

\section{INTRODUCTION}

Since its establishment in 1946, the English Department of Universitas Gadjah Mada (UGM) constantly uses English in its learning activities as the tool of communication between the teachers and the students. However, despite their daily practice, the students of the English Department of UGM still produced errors, especially in writing activity. It is because writing, among the four basic language skills, has more complicated process than the others. A writer needs to think not only the idea that he wants to deliver to the readers but also the right way to express their ideas in a written form.

Writing becomes more complex when it is done in academic process. Writing an essay, for instance, deals with some components such as topic and controlling idea, supporting ideas, logical order, cohesion and coherence, and grammatical range and accuracy. Among the five components above, grammatical range and accuracy are considered as the commonest, yet basic problem the students have.

Grammar is the essential component in language teaching and learning. Nunan (1999) states, "Grammar is a description of the structure of a language and the way in which linguistic units such as words and phrases are combined to produce sentences in the language." When the students have a good understanding of grammar system, they are able to construct sentences in an appropriate way. They will also be able to deliver their ideas, messages and feelings to the readers. On the other hand, when the students do not have a good understanding of grammar system, they will find difficulties in constructing sentences. The errors they produce in their writing will cause confusion and misunderstanding among the readers.

In 2012, the English Department of UGM has a curriculum with General English as one of the introductory subjects taught in two consecutive semesters while the students are in 
their first year. The subject consists of three subsubjects: writing, reading, and grammar. While the reading class deals with reading comprehension skills and grammar class with tenses and structure, writing class mostly deals with writing activity and requires implementation of materials conveyed in grammar class as well. For the final task, the students are required to write an article upon certain topics to measure whether or not they implement the materials well in the writing process.

There have been a number of attempts to investigate errors produced by the students of English Department of Universitas Gadjah Mada, including Susilowati (2009), Atibrata (2011), Adrianti (2011), Simbolon (2013), Sari (2014), and Sinaga (2015). Susilowati (2009) investigated grammatical errors produced by tour guides in Taman Sari Yogyakarta. The research data were collected by recording conversations made by the tourist they were guiding and by interviewing them to collect information about their backgrounds of education and life. She used the Surface Strategy Taxonomy proposed by Dulay, Burt, and Krashen (1982) to analyze the errors found. She also identified particularly the types of errors found based on the linguistic categories. The results show that the most common error was omission.

Atibrata (2011) investigated errors in using determiners made by the Indonesian students. The data were taken from the students' writing final examination in the General English Class B from the first year English Department students year 2010 of Universitas Gadjah Mada. The results suggest that most of the students tend to omit the use of articles in their writings. Although both this research and Atibrata's one investigated students of English Department of UGM, there is a difference between them since the two researches applied different theories. While Atibrata used Politzer and Ramirez' Linguistic Category, this research applied Surface Strategy Taxonomy proposed by Dulay, Burt, and Krashen (1982).

Another study on grammatical errors was conducted by Ardianti (2011). She investigated errors in the English version of the Indonesian Law of Extradition. The data source of her research was the English version of the Law of the Republic of Indonesia taken from a book entitled "EKSTRADISI (Inggris -Indonesia)" and the translation was done by NCB-INTERPOL Indonesia. The data took the forms of phrases and clauses containing grammatical errors. The errors were classified according to their syntactic forms. She found that the most common errors were in the use of passive voice.

Simbolon (2013) investigated errors found in the websites of three Indonesian Public Universities: Universitas Indonesia (UI), Universitas Gadjah Mada (UGM), and Universitas Airlangga (Unair). The data source chosen were only three sections from the website of each university, i.e. profile, history, and vision and mission as they were static and factual. After collecting the data, she analyzed the errors found according to the types of errors based on linguistic classification proposed by Politzer and Ramirez (1973). She found that the most common errors were in the use of determiners, specifically in the omission of the definite article.

Sari (2014) also investigated errors in the English version of Indonesia's official tourism website managed by the Ministry of Tourism and Creative Economy, the Republic of Indonesia. The data used in that research were taken from the articles containing grammatical errors. The results show that from 11037 words, 150 errors (13.59 per 1000 words) were found, where 131 belong to the syntactic category and only 19 belong to the morphological category. Furthermore, out of the 19 morphological errors, the most frequent errors occurred in the incorrect use of nominal modifiers. As for the syntactic errors, the most common occurred in the use of the noun phrase (102 errors), most of which happened because of the omission for the articles, especially the definite article. The results seem to reflect the ability of the writers which do not clearly understand about the occasions when the definite article must be used.

A recent study was conducted by Sinaga (2015). She investigated grammatical errors in the English version of an official Indonesia website entitled "Portal Nasional Republik Indonesia". In particular, it attempts to classify the errors based 
on Surface Strategy Taxonomy proposed by Dulay, Burt, and Krashen (1982). The research data were taken from articles on the website. The result shows errors in fifteen linguistic categories in the Surface Strategy Taxonomy which is divided into four parts, namely: omission, addition, misformation, and misordering. From all the four parts, she discovered that the most frequent errors found are in the part of misformation (188 errors; $78.96 \%$ ) followed by omission (39 errors; $16.38 \%$ ), addition (8 errors; $3.36 \%$ ) and misordering (2 errors; 0.84\%). While from the linguistic categories, the three most frequent errors found are the spelling with 74 errors (31.08\%), then parallelism with 62 errors (26.04\%), and the third is determiner with 21 errors (8.82\%). The research concludes that capability of the author in using accurate English still needs to be more developed in order to keep the reputation of the website.

The difference between this research and the previous ones is that this research was conducted in a formal academic institution. It is because we consider that the best way to teach and learn grammatical rules is in formal classes. Thus, this research focuses on grammatical errors found within the submitted assignments made by students of English Department of Universitas Gadjah Mada year 2012 in writing class. In identifying and classifying the errors, we classified the errors based on their linguistic category proposed by Dulay, Burt, and Krashen (1982).

Thus, this research attempts to analyze grammatical errors made by students of English Department of UGM year 2012 in their final paper of writing class. In particular, it aims to:

a) identify the grammatical errors that occur in their submitted assignments, and

b) classify the errors found according to their grammatical features.

The scope of this research is limited only to the grammatical errors. Since grammatical analysis cannot be done without syntactical and morphological analysis, this research also included the syntactical and morphological analysis. It does not carry out the semantic and pragmatic analysis.

\section{METHODS}

The data for this research were taken from the submitted assignments of English Department students of Universitas Gadjah Mada year 2012 in General English, particularly in writing class. The class was held in two semesters from August, 2012 to June, 2013, for the first year students. The class had 63 students who were divided into three parallel smaller classes: class A 19 students; class B 21 students; and class C 23 students.

One of the learning activities requires the students to write an essay on certain topics related to the subject. Some essays were written in the class, while some others were take-home assignment. We randomly selected the works of three or four students from each class as the objects so that there are 9 texts ( 3 from each small class) to be investigated in this research.

The data collecting procedures are as follow. Each time a grammatical error was identified, it was noted down together with the essay and page number where it was found. The errors were underlined. After collecting the data, the next step was analyzing the errors. Errors that had been found were then classified according to their syntactic and morphological forms.

\section{THEORETICAL FRAMEWORK}

\section{Errors}

Dulay and Burt (in Richards, 1973) argue that "while the child is learning a second language, he will tend to use his native language structures in his second language speech, and where structure in his first language (L1) and his second language (L2) differ, he will goof."

According to Richards and Schmidt (2002), error is "use of a linguistic item (e.g. a word, a grammatical item, a speech act, etc.) in a way which a fluent or native speaker of the language regards as showing faulty or incomplete learning." Furthermore, Richards and Schmidt (2002) state that "errors are sometimes classified according to vocabulary (lexical error), misunderstanding of a speaker's intention or meaning (interpretive error), production of the wrong communicative 
effect, e.g. through the faulty use of a speech act or one rules of speaking (pragmatic error)."

In a language learning process, however, the term 'error' is not the same as 'mistake.' About this, Corder (1967 in Ellis, 1994) explains that "An error takes place when the deviation arises as a result of lack of knowledge. It represents a lack of competence. A mistake occurs when learners fail to perform their competence. Mistakes arise as a result of competing plans, memory limitation and lack of automaticity."

In addition, Richard and Schmidt (2002) state, "A distinction is made between errors, as a result from incomplete knowledge, and a mistake is made when the learner is writing or speaking and it is caused by lack of attention, carelessness, fatigue, or other aspects of performance." Error occurs because a learner is lack of competency or incompetence, while mistake does when a learner, though he has all the competency of the language, fails to perform what he knows.

Any take-home assignment, especially as a requirement of a final exam, is supposed to be checked and edited excessively before it is submitted. However, still some grammatical errors appear in the students' papers. It shows that it was more of a lack of grammatical competence in English rather than failure of performing the best action during the process of writing the assignments. Thus, according to the definitions given above, the term "error" is more suitable to be used in this research rather than mistake because the students should have checked their papers for several times before submitting them.

\section{Error Types}

Dulay, Burt, and Krashen (1982) state that second or foreign language learners might omit, add, misform or misorder items in a sentence. These tendencies are the focus of the Surface Strategy taxonomy as they highlight. The explanation of each of them is provided below:

\section{Omissions}

Omission errors occur when there is an absence of an item in a well-formed sentence. An example of omission errors is the omission of the preposition "of" in When the bell rings, the students go out the class. The sentence is incorrect because the preposition "of" that should appear after the preposition "out" is omitted.

\section{Additions}

Addition is the kind of error that occurs when an item appears in an inappropriate position. There are three kinds of addition errors, they are:

\section{Double Markings}

This occurs when there are two markers used for the same feature while only one marker is required, such as in $\mathrm{He}$ did not came for my birthday party last week.

\section{Regularization}

This type of errors happens when a marker that is typically added to a linguistic item is erroneously added to exceptional items of the given class that do not take the marker, such as: The childrens do not like ice cream. The suffix "s" should not appear as the word children is already a plural form of child.

\section{Simple Addition}

This happens when an error is neither a double marking nor regularization, such as: One of these the students will receive scholarship. It is incorrect since the articles these and the cannot be used together for one plural noun.

\section{Misformations}

Misformation is the kind of error when the morpheme or structure is incorrectly used. There are three parts included in this type, they are:

\section{Regularization Errors}

It is when a regular marker is used in place of an irregular one, as in putted for put, foots for feet, or theirselves for themselves. 


\section{Archi-forms}

This kind of error happens when the selection of one number of a class of forms occurs to represent others in the class, such as in This books belong to me.

\section{Alternating Forms}

It is when the use of archi-forms often gives way to the apparently fairly free alternation of various members of a class with each other, for example, in the case of pronouns, masculine for feminine (or vice versa), plural for singular (or vice versa), and accusative for nominative (or vice versa). Moreover, in participle form, it is as in $I$ seen you last week.

\section{Misorderings}

Misordering is the incorrect placement of a morpheme or group of morphemes in a sentence, such as I don't know what is her name instead of $I$ don't know what her name is.

\section{RESULTS AND DISCUSSION}

From the 9 texts analyzed, 178 errors were found in various linguistic categories. The frequency and distribution of errors per section from each essay are shown in Table 1 below along with the calculation of the occurrence of errors per 1,000 words.

Table 1. The frequency and distribution of errors across 9 texts

\begin{tabular}{rrrr}
\hline Texts & $\begin{array}{c}\text { Total } \\
\text { Number } \\
\text { of Words }\end{array}$ & $\begin{array}{c}\text { Total } \\
\text { Number } \\
\text { of Errors }\end{array}$ & $\begin{array}{c}\text { Errors } \\
\text { per 1,000 } \\
\text { Words }\end{array}$ \\
\hline 1 & 457 & 57 & 125 \\
\hline 2 & 369 & 15 & 41 \\
\hline 3 & 503 & 31 & 62 \\
\hline 4 & 151 & 14 & 93 \\
\hline 5 & 603 & 36 & 60 \\
\hline 6 & 219 & 8 & 37 \\
\hline 7 & 264 & 8 & 30 \\
\hline
\end{tabular}

\begin{tabular}{rrrr}
\hline 8 & 140 & 6 & 43 \\
\hline 9 & 294 & 3 & 10 \\
\hline Total & 3000 & 178 & 59 \\
\hline
\end{tabular}

Table 1 above shows that text 1 has the highest score of all with 57 errors. As mentioned before, the total number of errors is then divided by the total number of words times 1000 to obtain the occurrence of errors per 1000 words. Therefore, it can be concluded that text 1 has 125 errors per 1000 words. Indeed, text 1 is the only one that has the number of occurrence of errors above 100 errors per 1,000 words. The detailed numbers of errors tell us at one point that an English Department student of UGM still has a chance to produce a lot of errors in English writing. It tells us that some students, just as the author of text 1 , may have many difficulties in their writing activity. It is not good as the more errors they produce, the bigger possibility they have in causing confusion and misunderstanding in their writings. The further explanation will be delivered in the next part.

On the other hand, on the last place there is text 9 with only 3 errors found or 10 errors per 1,000 words. Text 7 contains only 8 errors found in 264 words or 30 errors per 1,000 words; Text 6 8 errors from 219 words (37 errors per 1,000 words); Text 215 errors in 369 words (41 errors per 1,000 words); and Text 86 errors in 140 words (43 errors per 1,000 words). It tells us that although there may be students who have lack of competency in writing, there are also few students who have fewer problems in English writing. It will come again to a point that the fewer errors they produce, the smaller possibility they have in causing confusion and misunderstanding.

The rest are text 5 with 36 errors found in 603 words (60 errors per 1,000 words), text 3 with 31 errors in 503 words (62 errors per 1,000 words), and text 4 with 14 errors in 151 words (93 errors per 1,000 words).

Table 1 also shows that the calculation of the total number of words from all the texts analyzed is as many as 178 (59 errors per 1,000 words), found by carefully reading all the words in total of 3,000 words. In other words, the percentage of errors is 59 
In further analysis, table 2 presents the data and information about the frequency and the distribution of all types of errors found in all the 9 texts. It explains more specific about the total errors of each four types of Surface Strategy Taxonomy in all four sections.

Table 2. The frequency and distribution of surface strategy errors

\begin{tabular}{rlrc}
\hline No. & Error Types & Number & $\%$ \\
\hline 1. & Addition & 20 & 11.24 \\
\hline 2. & Misformation & 97 & 54.49 \\
\hline 3. & Misordering & 23 & 12.92 \\
\hline 4. & Omission & 38 & 21.35 \\
\hline \multicolumn{2}{r}{ Total } & 178 & 100.00 \\
\hline
\end{tabular}

The errors identified are now classified based on the four types of Surface Strategy Taxonomy: omission, addition, misformation, and misordering along with the total number and percentage of each section.

Misformation has the highest number of errors with 97 errors or $54.49 \%$. This is quite many as the three other types are not more than its half. The errors in this type are found into all the 9 texts. Text 1 has the most errors with 38 errors found (66.67\%). In the second place there is text 5 with 16 errors (44.44\%) followed by Text 3 with 14 errors (45.16\%).

The second highest number of errors is omission type. It has 38 errors (21.35\%). Text 1 has the highest number with 12 errors (21.05\%), proceeded by text 5 with 10 errors (27.03\%), text 3 with 7 errors (22.58\%) and text 4 with 5 errors (35.71\%). Text 2, Text 6, Text 7, and Text 9 share the same number with only one error, while Text 8 contain more than one error.

The third type of taxonomy that has only 23 errors $(12.78 \%)$ is misordering. Only 5 of 9 texts that contains errors in this type, and they are Text 3 with 9 errors (29.01\%), Text 2 with 7 errors (46.67\%), Text 5 with 4 errors (10.81\%), Text 1 with 2 errors $(3.51 \%)$, and Text 4 with only 1 error $(7.14 \%)$.

The last is addition type that produces a slightly less number than the previous type with only 20 errors (11.11\%). Text 5 has the highest number with 6 errors (16.22\%), followed by Text 1 with 5 errors $(8.77 \%)$, text 7 with 4 errors (44.44\%), Text 8 with 3 errors (50\%), and Text 3 and Text 6 each have 1 error.

Table 3. The frequency and distribution of linguistic errors

\begin{tabular}{|c|c|c|c|}
\hline No. & Linguistic Category & Number & $\%$ \\
\hline 1. & Adjective & 2 & 1.12 \\
\hline 2. & Adverb & 3 & 1.69 \\
\hline 3. & Complex Sentence & 24 & 13.48 \\
\hline 4. & Conjunction & 17 & 9.55 \\
\hline 5. & Determiner & 30 & 16.85 \\
\hline & Noun & 5 & 2.81 \\
\hline 7. & Number & 15 & 8.43 \\
\hline & Parallelism & 2 & 1.12 \\
\hline & Passive Voice & 1 & 0.56 \\
\hline 10. & Preposition & 10 & 5.62 \\
\hline 11. & Pronoun & 13 & 7.30 \\
\hline 12. & $\begin{array}{l}\text { Subject-Verb } \\
\text { Agreement }\end{array}$ & 18 & 10.11 \\
\hline 13. & Tense & 3 & 1.69 \\
\hline 14. & Verbal & 35 & 19.66 \\
\hline & Total & 178 & 100 \\
\hline
\end{tabular}

Table 3 above shows the detailed occurrences of errors showing the number of each linguistic category or the type of errors as the determinant for resulting both number and percentage.

As previously mentioned, there are 178 errors found in a total of 9 texts, and they fall into 15 linguistic categories. The categories are presented with the taxonomy in order to discover the number and the percentage.

The following is the explanation for frequency of each category. We found that the most frequent error in the whole 9 texts is "verbal" with total 35 errors (19.44\%) found. They are distributed into three types: omission, 
addition, and misformation. The last mentioned type has the highest number with 30 errors $(85.71 \%)$, followed by addition with 4 errors $(11.43 \%)$ and omission with only 1 error (2.86\%).

The second most occurring error is "determiner" with 30 errors (16.67\%). This type is the same as the previous type that it occurs within omission, addition, and misformation. Omission has the most errors with 19 errors (63.33\%), proceeded by misformation with 6 errors (20\%). Meanwhile, addition has the lowest number with only 5 errors (16.67\&).

The third rank belongs to "complexsentence" which contains 24 errors (13.33\%). The errors are distributed into three types where misordering has the highest number with 20 errors (83.33\%). Misformation comes up with 3 errors $(12.50 \%)$ while addition has only 1 error (4.17\%).

The fourth most frequent error is "subjunctverb agreement" It has 18 errors (10\%) found in two types: misformation and misordering. Misformation contributes 17 errors while misordering only one for the same type of errors.

"Conjunction" is on the fifth position with total 17 errors (9.44\%), and the errors are distributed into omission, addition, and misformation. The highest number is in omission with 10 errors (58.82\%). Misformation proceeds with 5 errors (29.41\%). The last is addition which has only 2 errors (11.76\%).

The sixth most frequent error is "number" which has 15 errors (8.33\%). All the errors are categorized into only misformation type.

The seventh most frequent error is "pronoun" with 13 numbers (7.22\%). The errors are shared into three types: misformation with 6 errors (46.15\%), omission with 5 errors $(38.46 \%)$, and addition with 2 errors (15.38\%).

The eighth most frequent error is "preposition" which occurs 10 times (5.56\%) in the whole 9 texts. They are distributed to all the four types. Addition has the most errors with 5 errrors (50\%). Omission and misformation have the same number, i.e., 2 errors (20\%), while misordering has only 1 error (10\%).
The ninth position belongs to "noun" which has 5 errors $(2.78 \%)$ distributed to three types: omission, addition, and misformation. 3 errors (60\%) occur in misformation, but only 1 error is found in each omission and addition.

The tenth most frequent error is "tense" and "adverb" with 3 errors (1.67\%) for each. They also share the distribution of the errors to only one type: misformation.

"Parallelism" and "adjective" also share the same the next position with 2 errors $(1.11 \%)$ for each of them. However, the distribution of their errors vary in two types. While "Parallelism" distributes the errors to only misformation, "adjective" divides its two errors into misformation and misordering.

Finally, "passive voice" is the least frequent error to occur with only one error $(0.56 \%)$ in misformation type.

\section{CONCLUSION}

The research findings show that the highest frequency of errors is produced in text 1 with 57 errors or $12.47 \%$. The types of errors are misformation with 38 errors (66.67\%), omission with 12 errors (21.05\%), addition with 5 errors (8.77\%), and misordering with 2 errors (3.51\%).

Using the Surface Strategy Taxonomy, we found out that there are fifteen linguistic categories. They are determiner, preposition, pronoun, number, parallelism, conjunction, passive voice, tense, verbal, noun, adjective, complex sentence, subject-verb agreement, and adverb. The three most frequently occurring errors are found in the linguistic categories of verbal, determiner, and complex sentence. Furthermore, if they are combined with all four types of Surface Strategy Taxonomy, it is stated that the three most frequently occurring errors are misformasion of verbal (30 errors), misordering of complex sentence (20 errors), and omission of determiner (19 errors).

The results indicate that the students of English Department of UGM need to pay more attention in their writings because when they produce grammatical errors, their ideas may not be clearly delivered. Moreover it can cause 
confusion and misunderstanding among the readers.

The classes such as Writing Class and Grammar Class (both are parts of General English classes) are one good step. The students really need to pay full attention in these classes specifically, and all other classes generally to learn more about grammatical errors to improve their writing skills. In addition, we suggest that the activity of English writing should be paid more attention not only by the students, but also all the teachers constantly and endlessly. Hopefully, the students will improve their writing skills and produce fewer errors in their writing, both in academic activities and in any other field of authorship.

\section{REFERENCES}

Adrianti, U. (2011). Grammatical errors in the English version of the Indonesian law extradition. Unpublished graduating paper. Yogyakarta: Universitas Gadjah Mada.

Atibrata, T. G. (2011). Indonesian students' errors in the use of determiners. Unpublished graduating paper. Yogyakarta: Universitas Gadjah Mada.

Dulay, H., Burt, M. \& Krashen, S. (1982). Language two. Oxford: Oxford University Press.

Ellis, R. (1994). The study of second language acquisition. Oxford: Oxford University Press.

Nunan, D. (1999). Second language teaching and learning. Massachusetts: Heinle \& Heinle Publishers.
Politzer, R. L. \& Ramirez, A. G. (1973). An error analysis of the spoken English of MexicanAmerican pupils in a bilingual school and a monolingual school," Language Learning 23(10), 39-62.

Richards, J. C. (1973). Error analysis: Perspective on second language acquisition. London: Longman Limited Group.

Richards, J. C. \& Schmidt, R. (2002). Longman dictionary of teaching and applied linguistics. Edinburgh: Pearson Education.

Sari, M. E. C.. (2014). Grammatical errors in the English version of Indonesia's official tourism website. Unpublished graduating paper. Yogyakarta: Universitas Gadjah Mada.

Simbolon, C. O. (2013). Grammatical errors in the website of three Indonesian public universities. Unpublished graduating paper. Yogyakarta: Universitas Gadjah Mada.

Sinaga, A. G. H. (2015). Grammatical Errors on the Portal Nasional Indonesia Website. Unpublished graduating paper. Yogyakarta: Universitas Gadjah Mada.

Susilowati, A. (2009). English Grammatical Error Analysis of Guide's Utterance in Taman Sari, Yogyakarta, Indonesia. Unpublished graduating paper. Yogyakarta: Universitas Gadjah Mada. 